\section{Acute epiglottitis as the initial presentation of pediatric Systemic Lupus Erythematosus Sirirat Charuvanij ${ }^{1,2}$ and Kristin M Houghton*1,2}

\author{
Address: ${ }^{1}$ Division of Pediatric Rheumatology, British Columbia's Children's Hospital, Vancouver, Canada and ${ }^{2}$ University of British Columbia, \\ Vancouver, Canada \\ Email: Sirirat Charuvanij - scharuvanij@cw.bc.ca; Kristin M Houghton* - khoughton@cw.bc.ca \\ * Corresponding author
}

Published: 31 October 2009

Pediatric Rheumatology 2009, 7:19 doi:10.1186/1546-0096-7-19

This article is available from: http://www.ped-rheum.com/content/7/l/19

(C) 2009 Charuvanij and Houghton; licensee BioMed Central Ltd.

This is an Open Access article distributed under the terms of the Creative Commons Attribution License (http://creativecommons.org/licenses/by/2.0), which permits unrestricted use, distribution, and reproduction in any medium, provided the original work is properly cited.
Received: 9 July 2009

Accepted: 31 October 2009

\begin{abstract}
We report a case of a 5-year old girl, who initially presented with acute epiglottitis, sepsis and multiorgan failure. She was subsequently diagnosed as having Systemic Lupus Erythematosus. To the best of our knowledge, this article describes the first case of Haemophilus influenzae type fepiglottitis as the initial presentation of SLE in childhood.
\end{abstract}

\section{Introduction}

Systemic Lupus Erythematosus (SLE) is a periodic, multisystem, autoimmune disease characterized by the presence of antinuclear antibodies. Approximately $15 \%$ of SLE cases are diagnosed before the age of 16 and children often have more severe disease at onset and higher rates of organ involvement than adults [1]. We report a case of SLE with initial presentation of Haemophilus influenzae epiglottitis. Laryngeal involvement and pneumococcal epiglottitis have infrequently been reported in the adult literature [2-4]. This is the first pediatric case and the first case of Haemophilus influenzae epiglottitis reported in SLE.

\section{Case presentation}

A 5-year old fully immunized and previously healthy girl of Filipino origin presented to her local hospital with a one day history of high fever $\left(39^{\circ} \mathrm{C}\right)$, sore throat, stridor and shortness of breath. She was transferred to BC Children's Hospital and was intubated by an otolaryngologist in the operating room. Subsequently, she was admitted to the ICU and was intubated and ventilated for 3 days. A lateral neck radiograph revealed a profoundly swollen epiglottis and complete airway obstruction (Figure 1). The diagnosis of acute epiglottitis was made based on her clin- ical picture and imaging findings. She was empirically treated with intravenous Cefotaxime. Her throat swab and blood culture were positive for Haemophilus influenzae type $f$.

On day 2 of admission, she developed multi-organ system dysfunction with anemia, thrombocytopenia, acute renal failure and hypertension (BP 123/80 mmHg). Investigations revealed hemoglobin at $63 \mathrm{~g} / \mathrm{L}$, white blood cell $7 \times$ $10^{9} / \mathrm{L}$ with lymphocyte of $1.85 \times 10^{9} / \mathrm{L}$. Her platelets were $53,000 / \mathrm{mm}^{3}$. DAT was positive. PT and INR were normal. APTT and dilute Russell Viper time were elevated at $41 \mathrm{sec}$ (20.2-32.9) and 2.17 ratio (0.76-1.15) respectively. Fibrinogen and D Dimer were elevated. Her serum creatinine was $143 \mathrm{umol} / \mathrm{L}(<51)$. Urinalysis showed 10-20 $\mathrm{RBC} / \mathrm{hpf}$, protein $0.3 \mathrm{~g} / \mathrm{L}$ with hyaline and granular casts. Treatment included supportive care, antibiotic (Cefotaxime), red blood cell and platelet transfusions.

On day 7 of admission, she developed seizures which were felt to be due to severe hypertension (BP 170/100 $\mathrm{mmHg}$ ). Computed tomography (CT) brain revealed multiple areas of abnormal hypodensity in the subcortical white matter of both hemispheres (Figure 2). Magnetic 


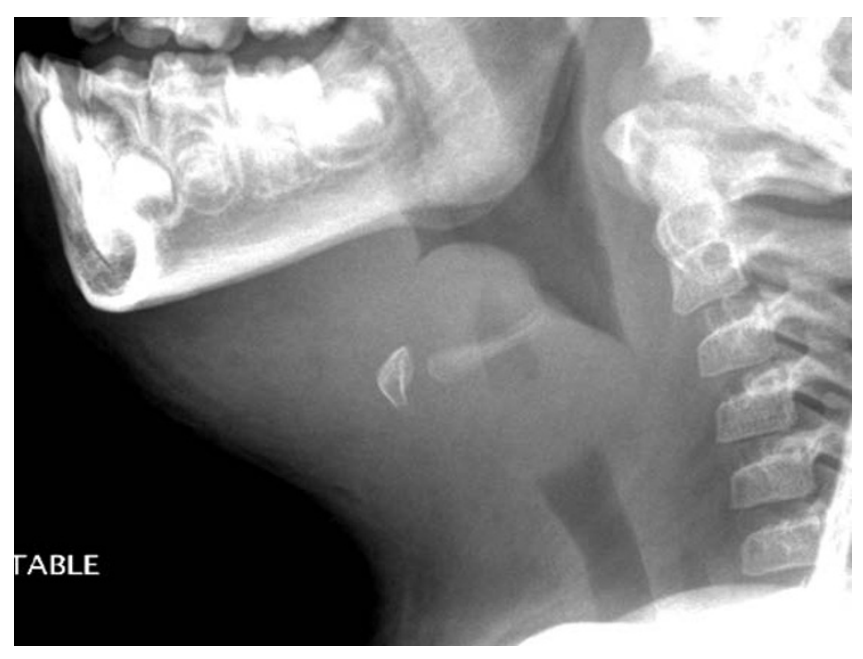

Figure I

A lateral neck radiograph demonstrates a profoundly swollen epiglottis and complete airway obstruction.

resonance imaging (MRI) brain demonstrated extensive T2 signal changes throughout the white matter with diffuse cerebral edema involving both cerebral hemispheres (Figure 3). A diagnosis of probable posterior reversible encephalopathy syndrome (PRES) was made.

On day 9 of admission, the rheumatology team was consulted. The main differential diagnosis at that time included SLE, Thrombotic Thrombocytopenic Purpura (TTP) and Wegener's Granulomatosis. A week later, her autoimmune and serologic workup came back positive for anti-nuclear antibody (ANA) at a titer of $>1: 1280$, positive anti-double stranded DNA, lupus anticoagulant, anticardiolipin antibody (ACA IgG was elevated at $6.1 \mathrm{MoM}$ ) and low complements C3 $(0.14 \mathrm{~g} / \mathrm{L})$ and C4 $(0.04 \mathrm{~g} / \mathrm{L})$. She underwent a renal biopsy which showed mesengial lupus nephritis (WHO class II) but due to a poor sample (only 4 glomeruli on light microscopy) the possibility of active proliferative lupus nephritis could not be excluded. Based on her clinical and laboratory findings, she was diagnosed with SLE and treated with a course of pulse Methylprednisolone $30 \mathrm{mg} / \mathrm{kg} /$ day for 3 days and subsequently converted to high dose oral prednisone $(2 \mathrm{mg} / \mathrm{kg} /$ day). She received her first Cyclophosphamide infusion $\left(500 \mathrm{mg} / \mathrm{m}^{2} /\right.$ dose) in the hospital prior to discharge.

She was discharged home on prednisone $(2 \mathrm{mg} / \mathrm{kg} /$ day $)$ with a scheduled taper, Hydroxychloroquine, Enalapril, Amlodipine and Clonazepam. She was scheduled to receive Cyclophosphamide infusions as an outpatient. At last assessment in our rheumatology clinic (9 months after initial presentation), her disease was in clinical remission. Her anti dsDNA was negative. C3 was slightly low at $0.71 \mathrm{~g} / \mathrm{L}$. C4 was normal. ENA panel remained neg- ative. She continued to have positive ANA at lower titer of 1: 640. She completed 8 courses of monthly Cyclophosphamide infusions and was switched to Mycofenolate Mofetil for maintenance immunosuppressant therapy.

\section{Discussion}

Epiglottitis is an inflammation of the epiglottis and the adjacent tissues surrounding the epiglottis. The clinical presentation includes abrupt onset of high fever, severe sore throat, dysphagia, "hot potato" voice, drooling and rapid progression of airway obstruction. Several bacteria have been associated with epiglottitis in children. Among them, Haemophilus influenzae type b was responsible for most cases of epiglottitis in pediatric patients in the preHib vaccine era [5].

Haemophilus influenzae is a pleomorphic gram-negative coccobacillus. There are encapsulated and non-encapsulated forms. After the initiation of Hib protein-polysaccharide conjugate vaccines, most cases of invasive Haemophilus influenzae infection have been attributed to non-type B strains [6]. Serology type $\mathrm{f}$ (Hif) is reported as the most common cause of invasive encapsulated non-b Haemophilus influenzae disease in children [7]. The risk of invasive Haemophilus influenzae disease include younger and older ages, complement deficiency, hypogammaglobulinemia, sickle cell anemia, functional asplenia, malignancy and HIV infection.

SLE is the prototypical multisystem autoimmune disease. Clinical manifestations of SLE are variable and the most common pediatric presentations include arthritis, malar rash, nephritis and central nervous system disease [8]. Our patient had lupus nephritis, hematological abnormalities, a positive ANA and a positive antibody to double stranded DNA, thus fulfilling four of the revised American College of Rheumatology classification criteria for SLE [9]. TTP was also initially considered given her thrombocytopenia, anemia, coagulopathy, fever, renal involvement and CNS involvement. TTP associated with SLE has been described [10-12]. However, her peripheral smear did not show typical microangiopathic changes of TTP and ADAMTS 13 was not performed. Furthermore, her seizure activity was thought to be due to PRES, not TTP or CNS lupus but the clinical presentations have considerable overlap and definitive diagnosis is challenging. PRES is a rapidly developing neurologic condition characterized by headache, decreased alertness, visual loss, seizures, hypertension and lesions in the posterior cerebral white matter. PRES was first reported in 1996 by Hinchey [13]. PRES associated with SLE has been reported in adults and children [13-17]. Our patient's MRI brain showed multiple hypodensity lesions in the subcortical white matter of both hemispheres, right post-central gyrus and on the left 


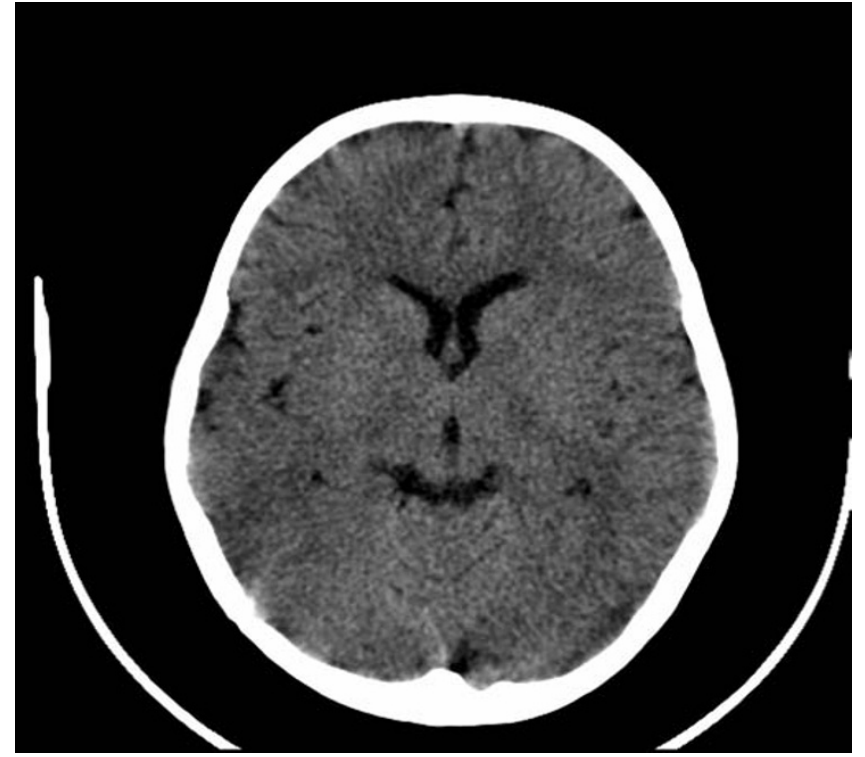

Figure 2

CT brain reveals multiple areas of abnormal hypodensity in the subcortical white matter of both hemispheres.

just at the central sulcus in keeping with the effects of hypertensive encephalopathy ("PRES").

Apart from the infection risk associated with immunosuppressive therapies, infection in SLE can be secondary to a primary defect in the immune system or alterations in the innate and adaptive immune responses. In addition, splenic dysfunction is reported in SLE patients $[18,19]$. One study reported $4.6 \%$ of SLE patients with functional asplenia [19]. These patients seem to have increased susceptibility to encapsulated bacteria including pneumococcal, meningococcal, Haemophilus influenzae and salmonella infection. Complement abnormalities are also reported in SLE patients resulting in defective opsonization of encapsulated organisms [20]. Even though infections occur commonly in SLE patients, it is rarely the presenting feature of the disease. The presentation of our patient with Haemophilus influenzae type f epiglottitis is unusual.

Although our patient did not have morphologic erythrocyte changes, it is possible that she developed splenic dysfunction during her initial clinical presentation of SLE. This may explain an increased susceptibility to Haemophilus influenzae. However, a 99m-technetium sulphur colloid scan and 99m- technetium labeled, heat-damage erythrocyte scan were not performed to support this hypothesis. The other hypothesis is that SLE is induced by Haemophilus influenzae infection. It is reported that bacterial DNA can enhance several of the autoimmune abnor- malities observed in SLE and perhaps play a pathogenic role in the induction of SLE [21]. There is a report of Haemophilus influenzae type f pericarditis and tamponade as the initial manifestation of systemic lupus erythematosus in an adult [22]. There are no reports of epiglottitis as the initial presentation of SLE in the literature but there are case reports of pneumococcal epiglottitis in adults with SLE and lupus overlap syndrome [2,3]. Laryngeal involvement in adult SLE ranges from mild ulcerations, vocal cord paralysis, laryngeal edema to necrotizing vasculitis with airway obstruction [4]. Furthermore, severe upper airway obstruction from cricoarythenoiditis was reported as the presenting manifestation of a SLE flare in an adult [23].

In conclusion, our pediatric patient presented with Haemophilus influenzae type $\mathrm{f}$ epiglottitis and septicemia and was subsequently diagnosed as having SLE. An opsonization defect and splenic dysfunction are most likely responsible for her increased susceptibility to infection with encapsulated bacteria. In addition, it is postulated that severe bacterial infection may play a role in inducing SLE. SLE has been called the "disease with a 1,000 faces" as it can present in many ways and it needs to be considered in the differential diagnosis of a sick child with multisystem disease. Clinicians need to be vigilant for infection in children with SLE as they may be at increased risk from their disease, functional hyposplenism and immunosuppressant therapy. Indeed, infection is the leading cause of

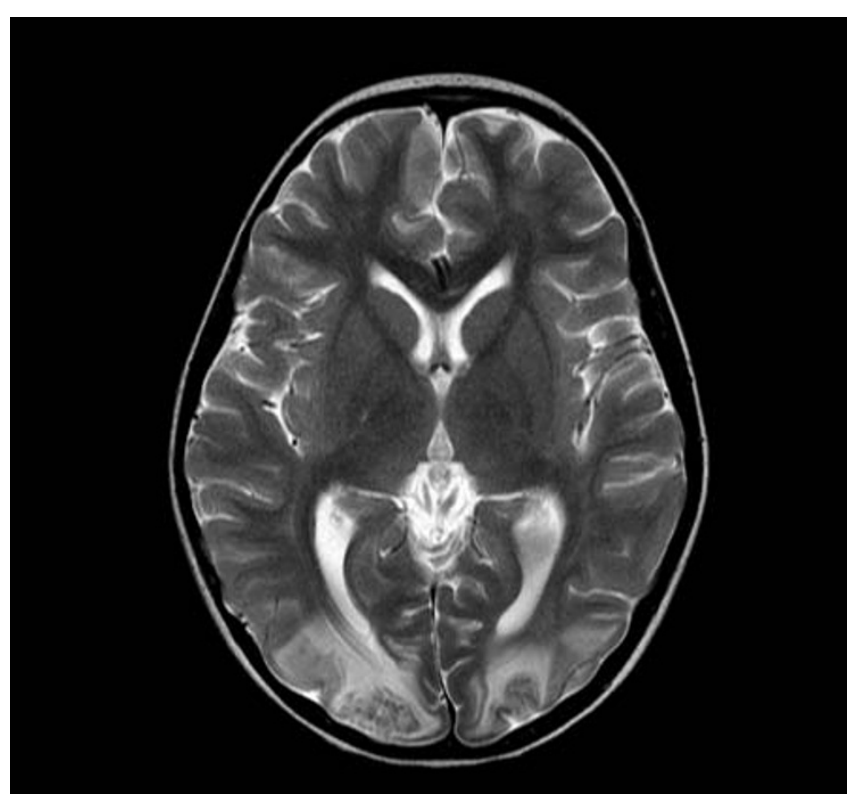

Figure 3

MRI brain shows extensive T2 signal changes throughout the white matter with diffuse cerebral edema involving both cerebral hemispheres. 
death in pediatric SLE [24]. Our clinical practice is to vaccinate all newly diagnosed SLE patients against encapsulated organisms.

\section{Competing interests}

The authors declare that they have no competing interests.

\section{Authors' contributions}

SC and KH participated in drafting the manuscript. All authors read and approved the final manuscript.

\section{Consent}

Consent was obtained from the parent of the patient for publication of this case report and accompanying images.

\section{References}

I. Tucker LB, Menon S, Schaller JG, Isenberg DA: Adult- and childhood-onset systemic lupus erythematosus: a comparison of onset, clinical features, serology, and outcome. $\mathrm{Br} J$ Rheumatol 1995, 34:866-872.

2. Isenberg DA, Lipkin DP, Mowbray JF, Fisher C, Davies R: Fatal pneumococcal epiglottitis in lupus overlap syndrome. Clin Rheumatol 1984, 3:529-532

3. Shalit M, Gross DJ, Levo Y: Pneumococcal epiglottitis in systemic lupus erythematosus on high-dose corticosteroids. Ann Rheum Dis 1982, 41:615-616.

4. Teitel AD, MacKenzie CR, Stern R, Paget SA: Laryngeal involvement in systemic lupus erythematosus. Semin Arthritis Rheum 1992, 22:203-214

5. Briem B, Thorvardsson O, Petersen H: Acute epiglottitis in Iceland 1983-2005. Auris Nasus Larynx 2009, 36:46-52.

6. McConnell A, Tan B, Scheifele D, Halperin S, Vaudry W, Law B, Embree !: Invasive infections caused by haemophilus influenzae serotypes in twelve Canadian IMPACT centers, 19962001. Pediatr Infect Dis J 2007, 26:1025-103I.

7. Urwin G, Krohn JA, Deaver-Robinson K, Wenger JD, Farley MM: Invasive disease due to Haemophilus influenzae serotype $\mathrm{f}$ : clinical and epidemiologic characteristics in the $\mathbf{H}$. influenzae serotype b vaccine era. The Haemophilus influenzae Study Group. Clin Infect Dis 1996, 22:1069-1076.

8. Hiraki LT, Benseler SM, Tyrrell PN, Hebert D, Harvey E, Silverman ED: Clinical and laboratory characteristics and long-term outcome of pediatric systemic lupus erythematosus: a longitudinal study. J Pediatr 2008, I 52:550-556.

9. Tan EM, Cohen AS, Fries JF, Masi AT, McShane DJ, Rothfield NF, Schaller JG, Talal N, Winchester RJ: The 1982 revised criteria for the classification of systemic lupus erythematosus. Arthritis Rheum 1982, 25: 127|-I277.

10. Dekker A, O'Brien ME, Cammarata RJ: The association of thrombotic thrombocytopenic purpura with systemic lupus erythematosus: A report of two cases with successful treatment of one. Am J Med Sci 1974, 267:243-249.

II. Caramaschi P, Riccetti MM, Pasini AF, Savarin T, Biasi D, Todeschini G: Systemic lupus erythematosus and thrombotic thrombocytopenic purpura. Report of three cases and review of the literature. Lupus 1998, 7:37-41.

12. Hamasaki K, Mimura T, Kanda H, Kubo K, Setoguchi K, Satoh T, Misaki Y, Yamamoto K: Systemic lupus erythematosus and thrombotic thrombocytopenic purpura: a case report and literature review. Clin Rheumatol 2003, 22:355-358.

13. Hinchey J, Chaves C, Appignani B, Breen J, Pao L, Wang A, Pessin MS Lamy C, Mas JL, Caplan LR: A reversible posterior leukoencephalopathy syndrome. N Engl J Med 1996, 334:494-500.

14. Magnano MD, Bush TM, Herrera I, Altman RD: Reversible posterior leukoencephalopathy in patients with systemic lupus erythematosus. Semin Arthritis Rheum 2006, 35:396-402.

15. Kur JK, Esdaile JM: Posterior reversible encephalopathy syndrome-an under recognized manifestation of systemic lupus erythematosus. J Rheumatol 2006, 33:2178-2 I83.
16. Min L, Zwerling J, Ocava LC, Chen IH, Putterman C: Reversible posterior leukoencephalopathy in connective tissue diseases. Semin Arthritis Rheum 2006, 35:388-395.

17. Punaro M, Abou-Jaoude P, Cimaz R, Ranchin B: Unusual neurologic manifestations (II): posterior reversible encephalopathy syndrome (PRES) in the context of juvenile systemic lupus erythematosus. Lupus 2007, 16:576-579.

18. Dillon AM, Stein HB, Kassen BO, lbbott JW: Hyposplenia in a patient with systemic lupus erythematosus. J Rheumatol 1980 , 7:196-198.

19. Neilan BA, Berney SN: Hyposplenism in systemic lupus erythematosus. Rheumatol 1983, 10:332-334

20. Walport MJ: The Roche Rheumatology Prize Lecture. Complement deficiency and disease. $\mathrm{Br} J$ Rheumatol 1993, 32:269-273.

21. Tomita H, Yamada M, Sekigawa I, Yoshiike T, lida N, Hashimoto H: Systemic lupus erythematosus-like autoimmune abnormalities induced by bacterial infection. Clin Exp Rheumatol 2003, 21:497-499.

22. Yeh YH, Chu PH, Yeh CH, Wu YJ, Lee MH, Jung SM, Kuo CT: Haemophilus influenzae pericarditis with tamponade as the initial presentation of systemic lupus erythematosus. Int J Clin Pract 2004, 58: 1045-1047.

23. Karim A, Ahmed S, Siddiqui R, Marder GS, Mattana J: Severe upper airway obstruction from cricoarytenoiditis as the sole presenting manifestation of a systemic lupus erythematosus flare. Chest 2002, I 21:990-993.

24. Wang LC, Yang YH, Lu MY, Chiang BL: Retrospective analysis of mortality and morbidity of pediatric systemic lupus erythematosus in the past two decades. J Microbiol Immunol Infect 2003, 36:203-208.

Publish with BioMed Central and every scientist can read your work free of charge

"BioMed Central will be the most significant development for disseminating the results of biomedical research in our lifetime. "

Sir Paul Nurse, Cancer Research UK

Your research papers will be:

- available free of charge to the entire biomedical community

- peer reviewed and published immediately upon acceptance

- cited in PubMed and archived on PubMed Central

- yours - you keep the copyright
BiolMedcentral 